\title{
IKERLANAK
}

\section{PARTIAL CROSS-OWNERSHIP AND STRATEGIC ENVIRONMENTAL POLICY}

\author{
by \\ Juan Carlos Bárcena-Ruiz and María Luz Campo
}

2011

Working Paper Series: IL. 47/11

Departamento de Fundamentos del Análisis Económico I

Ekonomi Analisiaren Oinarriak I Saila

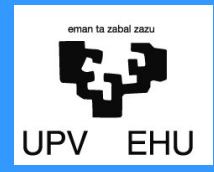

University of the Basque Country 


\title{
Partial cross-ownership and strategic environmental policy
}

\author{
Juan Carlos Bárcena-Ruiz and María Luz Campo* \\ Universidad del País Vasco
}

\begin{abstract}
This paper analyzes the effect that passive investment in rival firms has on the setting of cooperative and non-cooperative environmental taxes. We consider two firms located in different countries, one of which owns a stake in its rival. We show that partial cross-ownership affects the taxes set by the countries in the cooperative and non-cooperative cases. Depending on the stake that one firm has in its rival we show that cooperative taxes may be higher or lower than non-cooperative taxes. Moreover, for intermediate values of the stake, the non-cooperative tax is higher in one country and lower in the other than the cooperative tax.
\end{abstract}

Keywords: Environmental Taxes; International Trade; Local Pollution; Partial Ownership.

JEL Classification: Q58, F12, L13.

* Departamento de Fundamentos del Análisis Económico I, Facultad de Ciencias Económicas y Empresariales, Universidad del País Vasco. Avenida Lehendakari Aguirre 83, 48015 Bilbao, Spain. Phone: 34+946013829. Fax: 34+946013891. E-mails: juancarlos.barcena@ehu.es, mluz.campo@ehu.es. 


\section{Introduction}

There are many cases in which firms acquire a stake in their rivals that gives them a share in the profit but not in the decision making of those rivals (see Gilo et al., 2006). ${ }^{1}$ These passive investments affect the production and thus the pollutant emissions of the firms. As a result, partial cross-ownership affects the strategic environmental policy of governments. However, it is generally assumed in literature on the environment that each firm is owned by a different shareholder (see, for example, Ulph, 1996; Duval and Hamilton, 2002). This paper examines the setting of cooperative and non-cooperative environmental taxes set by governments when cross-participation exists at ownership level.

Determination of optimal environmental taxes has received considerable attention in the economic literature analyzing the environment. Pigouvian taxation is regarded as a benchmark according to which under perfect competition the optimal environmental tax is equal to the marginal environmental cost. However, as markets are not perfectly competitive it is of general interest to analyse optimal environmental taxes under imperfect competition. ${ }^{2}$

The problem of optimal environmental taxation considering a single market and imperfectly competitive firms was first analysed in Buchanan (1969) and then in Barnett (1980). They show that for an externality produced by a monopolist, the optimal tax is lower than the marginal environmental cost. The optimal tax consists of two parts: a Pigouvian tax (i.e. the marginal environmental cost), and a correction part due to the market power of the monopolist firm. This analysis has been extended to consider an oligopoly market. ${ }^{3}$

\footnotetext{
${ }^{1}$ For an explanation of why partial ownership arrangements are formed see Alley (1997). One of the reasons is that they alter the degree of competition in the industry (see, for example, Reynolds and Snapp, 1986; Farrell and Shapiro, 1990; Malueg, 1992; Ono et al., 2004; Gilo et al. 2006).

${ }^{2}$ See Requate (2006) for an excellent survey on this issue.

${ }^{3}$ In this regard see Simpson (1995), Katsoulacos and Xepapadeas (1995) and Carlsson (2000). They show that the optimal tax is not necessarily lower than the marginal environmental cost. Optimal environmental policies have also been analyzed assuming that firms produce differentiated products (see, for example, Katsoulacos and Xepapadeas, 1996; Lange and Requate, 1999; and Fujiwara, 2009), and that private firms compete with public firms (see Bárcena-Ruiz and Garzón, 2006).
} 
The literature on the environment has also analyzed strategic environmental policy when there is international trade and firms are imperfectly competitive. Considering Cournot competition, in this framework Barrett (1994) and Ulph (1996) show that when the firms located in each country are domestic-owned, national governments set emission standards such that the marginal cost of abatement is lower than the marginal damage caused by polluting emissions. Conrad (1993) assumes that firms sell in a third country's market and shows that non-cooperative emission tax rates are lower than the tax that would be set by the governments if they coordinated their policies so as to maximize the joint welfare of the countries. The same result is obtained by Conrad (1996a) and Kennedy (1994) assuming that firms sells their products in a single market (that includes domestic consumers) and assuming transboundary pollution. ${ }^{4}$

The design of environmental policy with imperfect competitive polluting industries has been extended to consider different types of asymmetries between countries. In this regard, Bárcena-Ruiz (2006) analyzes whether governments prefer to be leaders or followers in environmental policies when transboundary pollution is assumed. There is asymmetry in this model when the government sets taxes sequentially: otherwise the model is symmetric. ${ }^{5}$ In the cooperative equilibrium taxes are greater than in the non-cooperative equilibrium independently of whether taxes are set sequentially or simultaneously. In the non-cooperative equilibrium, both countries set the same tax under simultaneous decisions; however, under sequential decisions the leader government in taxes sets a higher (lower) tax than the follower if transboundary spillovers are low (high) enough.

\footnotetext{
${ }^{4}$ This analysis has been extended to consider Bertrand competition (see, for example, Conrad, 1996b; and Eerola, 2004). Another branch of the literature studies the interaction between strategic environmental policy and endogenous location of polluting firms (see, for example, Rauscher, 1995; Markusen, 1997; and Bárcena-Ruiz and Garzón, 2003).

${ }^{5}$ This paper shows that whether governments prefer to be leaders or followers in taxes depends on the degree to which environmental pollution spills over to trading partners. When this overspill is low (high) enough, taxes are strategic complements (substitutes) and governments set taxes sequentially (simultaneously).
} 
Duval and Hamilton (2002) extend the analysis of strategic environmental policy to consider market conditions characterized by various forms of international asymmetry. ${ }^{6}$ They find that in the cooperative equilibrium the optimal tax under asymmetric-cost oligopoly does not involve taxes harmonized between countries (i.e. governments set different taxes); for other forms of asymmetry, policy harmonization is optimal. In the case of unbalanced trade (i.e. domestic consumption does not equal domestic production), a net exporting country has an incentive to raise its tax because a portion of the tax is shifted onto prices, where it disproportionately affects foreign consumers. For a general distribution of the global consumer base, they find that the motivation of the domestic country to capture oligopoly rent for its firms is countervailed by the desire of the regulator to shift the burden of the tax onto foreign consumers. As a result, a net exporting (importing) country has an incentive to set higher (lower) environmental taxes than would be efficient under cooperation. ${ }^{7}$

In this paper we consider partial cross-ownership which means a different type of asymmetry between countries from that in the papers cited above. Under partial crossownership one firm (firm $s$ ) owns a stake in its rival (firm $r$ ), but the control of each firm is exerted by its main shareholder. Firms are owned by investors from the country in which they are located: firm $i$ is owned by investors from country $i(i=r, s)$. Thus the ownership of the firms is asymmetrically distributed between investors from the two countries. We consider that pollution is local. The purpose of this paper is to investigate how partial cross-ownership affects the setting of cooperative and non-cooperative environmental taxes by governments.

The issue that we analyze in this paper can be illustrated by taking the automobile industry as an example. In this industry there are examples of partial cross-ownership of rivals, e.g. the French firm Renault has formed a partnership with the Japanese firm Nissan. Renault currently holds a $44.3 \%$ equity stake in Nissan Motor and Nissan Motor

\footnotetext{
${ }^{6}$ Asymmetries are expressed in terms of consumption (different number of consumers in each country), production (different numbers of firms in each country or different production costs), and environmental damage (various forms of transboundary pollution).

${ }^{7}$ In the case of balanced trade and no transboundary pollution, the optimal cooperative and non-cooperative taxes coincide. However, with transboundary pollution the net importer of pollution sets a lower tax than the net exporter as an incentive to increase domestic pollution.
} 
owns a $15 \%$ stake in Renault (see www.renault.com). ${ }^{8}$ Moreover, in advanced countries governments set environmental taxes to get firms to internalize the damage generated by their pollutant emissions (see, for example, European Environmental Agency, 2007). We set our model in this context.

We consider first that countries set the environmental taxes that maximize the joint welfare of the two countries (cooperative taxes). ${ }^{9}$ Partial cross-ownership of firm $s$ reduces its production and emissions, which is taken advantage of by its rival to increase its own production and emissions. As a result, partial cross-ownership provides incentive for the countries to decrease the tax paid by firm $s$ to avoid an excessive reduction of its production; however, it encourage the countries to increase the tax paid by the other firm to reduce its greater local environmental damage. As a result, equilibrium taxes are not harmonized and firm $s$ (firm $r$ ) pays a less (more) tax than when there is no partial cross-participation.

In the non-cooperative case, given that there is strategic interaction between governments when setting environmental taxes, the following effects are present: first, the rent capture effect, which lowers equilibrium taxes as each country attempts to gain a competitive advantage over the other; second, the pollution-shifting effect, which raises equilibrium taxes as each country attempts to transfer production and its associated pollution to the other. Finally, the above effects are influenced by partial cross-ownership. On the one hand, partial cross-ownership reduces market competition by increasing (decreasing) the incomes obtained by country $s$ (country $r$ ). This means that the incentive to reduce taxes to capture rents from foreigners, the rent capture effect, is weakened for country $s$ and strengthened for country $r$. On the other hand, firm $s$ (firm $r$ ) produces and

\footnotetext{
${ }^{8}$ Another example is the partial acquisition of Wilkinson by Gillette: Gillette acquired $22.9 \%$ of the nonvoting stock and approximately $13.6 \%$ of the debt of Wilkinson Sword, one of its largest rivals (see Gilo et al., 2006); the first firm is from the U.S.A while the second firm is from the U.K.

${ }^{9}$ When there is no cross-ownership the model is symmetric which implies that equilibrium taxes are harmonized (i.e. both governments set the same tax). As firms have market power and their production processes damage the environment, it is well known (see Barnett, 1980) that a tax on pollution emissions reduces the environmental damage caused by firms but also causes them to reduce their production further (from already sub-optimal levels). Therefore, environmental taxes are below marginal environmental damage to avoid an excessive reduction of production by firms.
} 
pollutes less (more) than when there is no partial cross-ownership. As a result, the incentive to increase taxes to move production and its associated pollution to the other country, the pollution-shifting effect, is weakened for country $s$ and strengthened for country $r$. Thus, country $r$ (country $s$ ) sets a higher (lower) tax than when there is no partial cross-ownership since the pollution-shifting effect (the rent capture effect) dominates.

We next compare cooperative and non-cooperative taxes. Given that the rent capture effect dominates the polluting-shifting effect, when there is no partial cross-ownership non-cooperative taxes are lower than cooperative taxes (see Kennedy, 1994). However, this result changes under partial cross-ownership. In country $s$ the tax set in the cooperative and non cooperative cases decreases with the stake that its domestic firm has in the foreign firm. However, the cooperative tax decreases more than the non-cooperative tax with that stake since in the latter case the pollution-shifting effect dominates, which weakens the incentive to reduce the tax. As a result, the non-cooperative tax is higher than the cooperative tax when the stake is great enough. In country $r$ the tax set in both cases increases with the stake that foreign investors have in the domestic firm. However, the tax set in the non-cooperative case increases more than the tax set in the cooperative case with that stake since in the first case the pollution-shifting effect dominates the rent capture effect, which provides an additional incentive to increase the tax. As a result, the tax set in the non-cooperative case is higher than the tax set in the cooperative case if the stake is great enough. Therefore, if the stake is great (small) enough, both countries set a lower (higher) tax in the non-cooperative case. Finally, if the stake takes an intermediate value, country $s$ (country $r$ ) sets a lower (higher) tax in the non-cooperative case.

We extend the model to analyze whether the results obtained in the paper change when pollution is transboundary. Denote as transboundary spillovers the degree to which environmental pollution spills over to trading partners. We find that when transboundary spillovers are great enough cooperative taxes are higher than non-cooperative taxes. As the incentive to transfer production (and, thus, pollution) to the other country is weaker, the higher the value of transboundary spillovers the weaker the pollution-shifting effect is. Therefore, transboundary spillovers weaken the incentive of each country to raise the tax to send production abroad. As a result, when transboundary spillovers are great enough, the 
cross-ownership effect is weak enough to raise the taxes set by the governments above the cooperative taxes. When transboundary spillovers are low enough, we obtain a result similar to when environmental damage is purely local.

The rest of the paper is organized as follows. Section 2 presents the model. Section 3 and 4 analyze the environmental taxes set by governments in the cooperative and noncooperative cases respectively. Section 5 considers transboundary spillovers and Section 6 draws conclusions.

\section{The model}

We consider a world market comprising two countries denoted by 1 and 2 . There is one firm located in each country and the two firms produce a homogeneous good whose production process damages the environment. Firm $i$ is located in country $i, i=1,2$. There is free trade and the firms sell their products in the world market. There are no transportation costs, and there is no possibility of discriminating between consumers from different countries.

We assume that partial cross-ownership exists. Firm 1 owns the $\alpha$ percent of the stock of firm 2, $\alpha<1 / 2$; thus, it does not have a share in its rival's decision making. Firm 1 is owned by a single owner. As firm 1 owns $\alpha$ percent of the stock of firm 2 it chooses the output level $q_{1}$ that maximizes $\pi_{1}+\alpha \pi_{2}$. Firm 2 chooses the output level $q_{2}$ that maximizes $(1-\alpha) \pi_{2}$. We assume that investors from country 1 own firm 1 and thus $\alpha$ percent of the stock of firm 2. The rest of the stock of firm 2, (i.e. the $1-\alpha$ percent) is owned by investors from country 2.

The inverse demand function of country $i$ is given by: $p=A-2 y_{i}, i=1,2$, where $p$ is the world market price of the good and $y_{i}$ is the amount of the good sold in country $i$. Therefore, demand from the world market is given by the following inverse demand function: $p=A-q_{1}-q_{2}$, where $y_{1}+y_{2}=q_{1}+q_{2}$. Let $q_{i}$ denote the amount of the good that firm $i$ sells on the world market. The consumer surplus in country $i$ is given by: 


$$
C S_{i}=\left(y_{i}\right)^{2}, i=1,2 \text {. }
$$

There is a pollutant associated with the production of the good. Specifically, each unit of output causes one unit of pollutant emissions. However, firms have technology available for abating this pollution. Firms can abate emissions, and so we denote by $a_{i}$ the abatement level of firm $i$. As a result, the total pollutant emissions level of firm $i, e_{i}$, is: $e_{i}=$ $q_{i}-a_{i}$. Abating emissions entails a positive cost, and the total cost of pollution abatement is given by: $C\left(a_{i}\right)=k\left(a_{i}\right)^{2}$.

Firm $i$ pays an environmental tax, $t_{i}$, per unit of pollution emitted. This tax is chosen by government $i$. Therefore, the total taxes collected by government $i$, are $T_{i}=t_{i} e_{i}$. Given that each firm has to pay an environmental tax per unit of pollution emitted, the profit of firm $i$ is:

$$
\pi_{i}=\left(A-q_{i}-q_{j}-c\right) q_{i}-t_{i}\left(q_{i}-a_{i}\right)-k\left(a_{i}\right)^{2}, i \neq j ; i, j=1,2 .
$$

We consider local environmental damage and, thus, the polluting emissions of each firm affect only the country in which the firm is located. Specifically, we assume a quadratic functional form in the emission level to measure the environmental damage caused in country $i$ by firm $i:{ }^{10}$

$$
D_{i}=\lambda\left(e_{i}\right)^{2}, i=1,2
$$

where parameter $\lambda$ measures the valuation of the environment by government $i$.

The social welfare function considered by government $i$ comprises the consumer and producer surpluses in country $i$ (denoted by $C S_{i}$ and $P S_{i}$, respectively) the total taxes

\footnotetext{
${ }^{10}$ The literature on the environment usually assumes that environmental damage is a convex function of the total pollution level. See, for example, Falk and Mendelsohn (1993), Van der Ploeg and Zeeuw (1992), Ulph (1996), and Bárcena-Ruiz (2006).
} 
collected by government $i\left(T_{i}\right)$ and the environmental damage caused by the production process in country $i\left(D_{i}\right)$. Specifically, the social welfare function for country $i$ is:

$$
W_{i}=C S_{i}+P S_{i}+T_{i}-D_{i}, i=1,2,
$$

where $P S_{1}=\pi_{1}+\alpha \pi_{2}$ and $P S_{2}=(1-\alpha) \pi_{2}$.

We consider the following timing. In the first stage, environmental taxes are set simultaneously. In the second stage, the firms simultaneously choose their output and pollution abatement levels. We solve the game by backward induction from the last stage of the game to obtain a subgame perfect Nash equilibrium. For the sake of simplicity we assume that $k=1$ and $\lambda=1$. The main results hold for values of parameters $k$ and $\lambda$ other than 1 .

\section{Optimal environmental taxes in the cooperative case.}

Next we consider the cooperative policy outcome denoted by superscript $C$. In that case, countries set the taxes that maximize the joint welfare of the two countries. In the second stage, firms simultaneously choose the output and abatement levels that maximize their objective functions. As firm 1 owns $\alpha$ percent of the stock of firm 2 it chooses the output level $q_{1}$ that maximizes $\pi_{1}+\alpha \pi_{2}$. Firm 2 chooses the output level $q_{2}$ that maximizes (1$\alpha) \pi_{2}$. Solving these problems we obtain the equilibrium output and abatement levels, as a function of environmental taxes:

$$
q_{1}=\frac{(A-c)(1-\alpha)-2 t_{1}+t_{2}(1+\alpha)}{3-\alpha}, q_{2}=\frac{A-c+t_{1}-2 t_{2}}{3-\alpha}, a_{1}=\frac{t_{1}}{2}, a_{2}=\frac{t_{2}}{2} .
$$

From expression (5) we obtain that the output level of firm 2 increases with parameter $\alpha$ while the output level of firm 1 decreases with this parameter, for a given value of $t_{1}$ and $t_{2}$. When firm 1 chooses the output level $q_{1}$ it takes into account how it affects the profit of its rival. Thus, the higher the value of parameter $\alpha$ the lower the output level of firm $1, q_{1}$, and the higher the output level of firm 2, $q_{2}$. Moreover, the output of industry decreases with 
parameter $\alpha$, which means that cross-ownership reduces market competition. Expression (5) also shows that $a_{i}=t_{i} / 2$, which is just the usual condition that firm $i$ abates pollution to the point where marginal abatement cost equals the tax.

Next we solve the first stage of the game. In this stage the taxes $t_{1}$ and $t_{2}$ are chosen such that the joint welfare of the two countries, $W_{1}+W_{2}$, is maximized. Solving this we obtain the reaction functions in environmental taxes:

$$
\begin{aligned}
& t_{1}=\frac{(A-c)\left(4-8 \alpha+\alpha^{2}\right)+t_{2}\left(13+6 \alpha-\alpha^{2}\right)}{32-10 \alpha+\alpha^{2}}, \\
& t_{2}=\frac{2(A-c)\left(2+\alpha^{2}\right)+t_{1}\left(13+6 \alpha-\alpha^{2}\right)}{4\left(8-2 \alpha+\alpha^{2}\right)} .
\end{aligned}
$$

It is easy to see from (6) that environmental taxes are strategic complements $\left(\partial t_{i} / \partial t_{j}>0, i \neq j ; i, j=1,2\right)$; that is, if the tax set in one country rises (falls) the tax set in the other country also rises (falls). Denote by $t^{C}$ the tax set in the two countries when there is not partial cross-ownership (i.e. when $\alpha=0$ ); in this case the model is symmetric and both governments set the same tax. Solving, we obtain the following result.

Proposition 1. When environmental taxes maximize the joint welfare of the two countries:

i) $\frac{\partial t_{1}^{C}}{\partial \alpha}<0, \frac{\partial t_{2}^{C}}{\partial \alpha}>0, t_{1}^{C}<t^{C}<t_{2}^{C}$;

ii) $\frac{\partial D_{1}^{C}}{\partial \alpha}<0, \frac{\partial D_{2}^{C}}{\partial \alpha}<0, D_{1}^{C}<D_{2}^{C}$.

iii) $\frac{\partial W_{1}^{C}}{\partial \alpha}>0, \frac{\partial W_{2}^{C}}{\partial \alpha}<0, \frac{\partial\left(W_{1}^{C}+W_{2}^{C}\right)}{\partial \alpha}<0, W_{1}^{C}>W_{2}^{C}$.

Proof. See Appendix.

Given that in the cooperative case environmental taxes maximize the joint welfare of the two countries these taxes are chosen for efficiency reasons. As we consider imperfectly 
competitive firms whose production process generates pollution that damages the environment two effects have to be taken into account (see Barnett, 1980) to explain the result shown in this proposition: first, the underproduction associated with the exercise of the market power of firms (the underproduction effect); and second, in the absence of environmental policies polluting firms do not internalize the environmental damage caused by their polluting emissions (the pollution-internalization effect). Thus, when there is not partial cross-ownership (i.e. when $\alpha=0$ ) a tax on pollutant emissions reduces the environmental damage caused by firms but also causes firms to reduce their production further (from already sub-optimal levels). Therefore, the underproduction effect dominates and thus environmental taxes are below marginal environmental damage to avoid an excessive reduction in production by firms. ${ }^{11}$ In this case, as the model is symmetric, equilibrium taxes are harmonized, which means that both governments set the same tax, $t^{C}$.

Under partial cross-ownership an additional effect arises (the cross-ownership effect) that influences the two effects mentioned above. First, for given taxes, cross-ownership reduces the output of industry and thus market competition. As a result, the underproduction effect (and thus the incentive of governments to lower taxes) is strengthened; this effect is the same for both governments since both countries obtain the same consumer surplus. Secondly, for given taxes, as firm 1 owns $\alpha$ percent of the stock of firm 2 it reduces its own production and emissions with parameter $\alpha$, which is taken advantage of by firm 2 to increase its own production and emissions. As a result, crossownership strengthens (weakens) the incentive of the countries to increase the tax paid by firm 2 (1) to get this firm to internalize the damage caused by its pollutant emissions. Therefore, in country 1 the underproduction effect dominates and thus $t_{1}^{C}$ decreases with parameter $\alpha$. However, in country 2 the pollution-internalization effect dominates and thus $t_{2}^{C}$ increases with parameter $\alpha$. This means that taxes are not harmonized and the tax set in country 2 (1) is higher (lower) than when there is no cross-ownership: $t_{1}^{C}<t^{C}<t_{2}^{C} \cdot{ }^{12}$

\footnotetext{
${ }^{11}$ From (3), marginal environmental damage is: $M E D_{i}=2 e_{i}$. Thus, it is easy to see that $M E D_{1} C=2(A-c)(15-4 \alpha-$ $\left.\alpha^{2}\right) /\left(95-18 \alpha+3 \alpha^{2}\right), M E D_{2}{ }^{C}=(A-c)\left(30-6 \alpha-\alpha^{2}\right) /\left(95-18 \alpha+3 \alpha^{2}\right)$, and $M E D_{i}{ }^{C} t_{i}{ }^{C}$ for all $\alpha, i=1,2$.

${ }^{12}$ As the underproduction effect is strengthened by the cross-ownership effect, marginal environmental damage is greater than the tax in both countries.
} 
The environmental damage suffered by the two countries decreases with parameter $\alpha$. The tax set in country 1 (and thus its abatement level) decreases with parameter $\alpha$, which has less effect than the reduction in its output level, implying that its emission level and the environmental damage decrease with this parameter. The tax set in country 2 (and thus its abatement level) increases with parameter $\alpha$, which has a greater effect than the increase in its output level, implying that its emission level and the environmental damage decrease with this parameter. Finally, environmental damage in the two countries is lower than when there is no partial cross-ownership, and the environmental damage is greater in country 2 than in country 1 due to the greater pollutant emissions of firm 2 .

As the producer surplus in country 1 increases with parameter $\alpha$ while the producer surplus in country 2 decreases with this parameter, the effect of cross-ownership on the producer surplus implies that $\partial W_{1}^{C} / \partial \alpha>0, \partial W_{2}^{C} / \partial \alpha<0$ and $W_{1}^{C}>W_{2}^{C}$. As the reduction in the social welfare of country 2 has a greater effect than the increase in the social welfare of country 1, joint welfare decreases with parameter $\alpha\left(\partial\left(W_{1}^{C}+W_{2}^{C}\right) / \partial \alpha<0\right)$.

\section{Optimal environmental taxes in the non-cooperative case.}

Next we consider the non-cooperative case, denoted by superscript $N C$. In the second stage, firms simultaneously choose the output and abatement levels that maximize their objective functions. Solving these problems we obtain expression (5). In the first stage of the game, governments simultaneously set the environmental taxes that maximize their social welfare functions, given by (4). Solving these problems we obtain the reaction functions in environmental taxes:

$$
\begin{aligned}
& t_{1}=\frac{(A-c)\left(10-13 \alpha+2 \alpha^{2}\right)+t_{2}\left(13+9 \alpha-2 \alpha^{2}\right)}{65-24 \alpha+2 \alpha^{2}}, \\
& t_{2}=\frac{(A-c)\left(10+7 \alpha-\alpha^{2}\right)+t_{1}(13+3 \alpha)}{65-\alpha-5 \alpha^{2}+\alpha^{3}} .
\end{aligned}
$$


As in the cooperative case, taxes are strategic complements. Denote by $t^{N C}$ the tax set by each government when there is not partial cross-ownership (i.e. when $\alpha=0$ ). From (7) we obtain the following result.

\section{Proposition 2. In equilibrium:}

i) $\frac{\partial t_{1}^{N C}}{\partial \alpha}<0, \frac{\partial t_{2}^{N C}}{\partial \alpha}>0, t_{2}^{N C}>t^{N C}>t_{1}^{N C}, \frac{\partial a_{1}^{N C}}{\partial \alpha}<0, \frac{\partial a_{2}^{N C}}{\partial \alpha}>0, a_{2}^{N C}>a_{1}^{N C}$;

ii) $\frac{\partial q_{1}^{N C}}{\partial \alpha}<0, \frac{\partial q_{2}^{N C}}{\partial \alpha}<0, q_{2}^{N C}>q_{1}^{N C}, \frac{\partial \pi_{1}^{N C}}{\partial \alpha}>0, \frac{\partial \pi_{2}^{N C}}{\partial \alpha}>0, \pi_{1}^{N C}>\pi_{2}^{N C}$;

iii) $\frac{\partial C S_{1}^{N C}}{\partial \alpha}=\frac{\partial C S_{2}^{N C}}{\partial \alpha}<0, C S_{1}^{N C}=C S_{2}^{N C}$;

iv) $\frac{\partial P S_{1}^{N C}}{\partial \alpha}=\frac{\partial\left(\pi_{1}^{N C}+\alpha \pi_{2}^{N C}\right)}{\partial \alpha}>0, \frac{\partial P S_{2}^{N C}}{\partial \alpha}=\frac{\partial(1-\alpha) \pi_{2}^{N C}}{\partial \alpha}<0, P S_{1}^{N C}>P S_{2}^{N C}$;

v) $\frac{\partial T_{1}^{N C}}{\partial \alpha}<0, \frac{\partial T_{2}^{N C}}{\partial \alpha}>0, T_{2}^{N C}>T_{1}^{N C}, \frac{\partial D_{1}^{N C}}{\partial \alpha}<0, \frac{\partial D_{2}^{N C}}{\partial \alpha}<0, D_{1}^{N C}>D_{2}^{N C}$;

vi) $\frac{\partial W_{1}^{N C}}{\partial \alpha}>0, \frac{\partial W_{2}^{N C}}{\partial \alpha}<0, \frac{\partial\left(W_{1}^{N C}+W_{2}^{N C}\right)}{\partial \alpha}<0, W_{1}^{N C}>W_{2}^{N C}$.

Proof. See Appendix.

Given that there is strategic interaction between governments when setting environmental taxes, when there is no partial cross-ownership the result obtained in this proposition is explained by two effects: first, the rent capture effect, which lowers equilibrium taxes as each country attempts to gain a competitive advantage over the other (a unilateral reduction in the domestic tax rate has the potential to raise net exports and so permits the capture of rent from foreigners); and second the pollution-shifting effect, which raises equilibrium taxes as each country attempts to transfer production and its associated pollution to the other country.

Under partial cross-ownership an additional effect -the cross-ownership effect- arises that influences the two effects mentioned above. First, as partial cross-ownership reduces market competition the profit of both firms increases with parameter $\alpha$ and the incomes 
obtained by the investors of country 1 (2) increase (decrease) with this parameter. This means that the incentive to reduce taxes to capture rents from foreigners (the rent capture effect) is weakened (strengthened) in country 1 (2). Second, for given taxes, firm 1 (2) produces and pollutes less (more) than when there is no cross-ownership. This means that the incentive to increase taxes to send production and thus its associated pollution to the other country (the pollution-shifting effect) is weakened (strengthened) in country 1 (2).

The pollution-shifting effect dominates in country 2 , which means that its tax increases with parameter $\alpha$. Thus, the abatement level of firm 2 increases also with this parameter. However, in country 1 the rent capture effect dominates, implying that its tax decreases with parameter $\alpha$. As a result, the abatement level of firm 1 decreases with this parameter. Given that $t_{1}^{N C}\left(t_{2}^{N C}\right)$ decreases (increases) with parameter $\alpha$, it is obtained that $t_{2}^{N C}>t^{N C}>t_{1}^{N C}$ and thus the abatement level of firm 2 is higher than that of firm $1\left(a_{2}^{N C}>a_{1}^{N C}\right)$.

As firm 1 takes into account how its output affects the profit of its rival firm, its output decreases with parameter $\alpha$; firm 2 takes advantage of this to increase its output but as $t_{2}^{N C}$ increases with parameter $\alpha$, its output decreases with this parameter. However, firm 2 obtains a greater market share than firm $1\left(q_{2}^{N C}>q_{1}^{N C}\right)$. Although firm 2 has a greater market share than firm 1, as this firm pays higher taxes and abates more emissions it obtains lower profits $\left(\pi_{1}^{N C}>\pi_{2}^{N C}\right)$. Finally, as cross-ownership reduces market competition, the output level of the firms decreases with parameter $\alpha$ and, thus, the profit of the firms increases with this parameter. ${ }^{13}$

Given that the demand of the consumers of both countries is identical we get that both countries obtain the same consumer surplus $\left(C S_{1}^{N C}=C S_{2}^{N C}\right)$. Moreover, as the output of firm $i$ decreases with parameter $\alpha, C S_{i}^{N C}$ also decreases with this parameter. Moreover, as investors from country 1 own $\alpha$ percent of the stock of firm 2, they obtain greater incomes

\footnotetext{
${ }^{13}$ It must be noted that when firms do not pollute the environment and thus there are not environmental taxes, firm 2 produces more than firm 1 and obtains greater profits (see, for example, Malueg, 1992).
} 
than the investors from country $2\left(P S_{1}^{N C}=\pi_{1}^{N C}+\alpha \pi_{2}^{N C}>P S_{2}^{N C}=(1-\alpha) \pi_{2}^{N C}\right)$. Finally, $P S_{1}^{N C}$ increases with parameter $\alpha$ and $P S_{2}^{N C}$ decreases with this parameter.

Although $a_{2}^{N C}>a_{1}^{N C}$, as $q_{2}^{N C}>q_{1}^{N C}$ and $t_{2}^{N C}>t_{1}^{N C}$ we obtain that $T_{2}^{N C}>T_{1}^{N C}$. On the other hand, environmental damage is greater in country 1 than in country $2\left(D_{1}^{N C}>D_{2}^{N C}\right)$ since although firm 2 produces more output than firm 1 it also abates more emissions. The environmental damage suffered by the two countries decreases with parameter $\alpha$ since both the output and emission levels of the firms decrease with this parameter. Therefore, partial cross-ownership reduces environmental damage in both countries.

Social welfare is greater in country 1 than in country $2\left(W_{1}^{N C}>W_{2}^{N C}\right)$ since the greater producer surplus has a stronger effect on social welfare than the lower environmental taxes collected by the government and the greater environmental damage. Social welfare in country 2 (1) decreases (increases) with parameter $\alpha$ since $P S_{2}^{N C}\left(P S_{1}^{N C}\right)$ decreases (increases) with this parameter. However, the joint welfare of the two countries decreases with parameter $\alpha$.

We next compare the result obtained when governments set taxes cooperatively with that obtained when governments set taxes non-cooperatively.

Proposition 3. In equilibrium:

i) $t_{1}^{N C}<t_{1}^{C}$ and $t_{2}^{N C}<t_{2}^{C}$ if $\alpha<\alpha_{2}, t_{1}^{N C}<t_{1}^{C}$ and $t_{2}^{N C}>t_{2}^{C}$ if $\alpha_{2}<\alpha<\alpha_{1}, t_{1}^{N C}>t_{1}^{C}$ and $t_{2}^{N C}>t_{2}^{C}$ if $\alpha>\alpha_{1}, 0<\alpha_{i}<1 / 2, i=1,2$;

ii) $D_{1}^{C}<D_{1}^{N C}$ and $D_{2}^{C}<D_{2}^{N C}$ if $\alpha<\alpha_{4}, D_{1}^{C}<D_{1}^{N C}$ and $D_{2}^{C}>D_{2}^{N C}$ if $\alpha_{4}<\alpha<\alpha_{3}, D_{1}^{C}>D_{1}^{N C}$ and $D_{2}^{C}>D_{2}^{N C}$ if $\alpha>\alpha_{3}{ }^{14}$

Proof. See Appendix.

${ }^{14} t_{i}^{N C}=t_{i}^{C}$ for $\alpha=\alpha_{i}(i=1,2), D_{1}^{N C}=D_{1}^{C}$ for $\alpha=\alpha_{3}$, and $D_{2}^{N C}=D_{2}^{C}$ for $\alpha=\alpha_{4}$, where $\alpha_{3}>\alpha_{1}>\alpha_{2}>\alpha_{4}$. 
When each firm has a single owner $(\alpha=0)$ there is no cross-ownership effect and thus the rent capture effect dominates the polluting-shifting effect in the two countries, implying that equilibrium taxes are lower than the taxes set in the cooperative case $\left(t^{N C}<t^{C}\right)$. Under partial cross-ownership both $t_{1}^{C}$ and $t_{1}^{N C}$ decrease with parameter $\alpha$. However, $t_{1}^{C}$ decreases more strongly than $t_{1}^{N C}$ with parameter $\alpha$ since in the non-cooperative case the pollutionshifting effect dominates the rent capture effect in country 1 , which weakens the incentive to reduce the tax. As a result, $t_{1}^{N C}$ is greater than $t_{1}^{C}$ if parameter $\alpha$ is great enough $\left(\alpha>\alpha_{1}\right)$. On the other hand, under partial cross-ownership both $t_{2}^{C}$ and $t_{2}^{N C}$ increase with parameter $\alpha$. However, $t_{2}^{N C}$ increases more strongly than $t_{2}^{C}$ with parameter $\alpha$ since in the noncooperative case the pollution-shifting effect dominates the rent capture effect in country 2 , which provides an additional incentive to increase the tax. As a result, $t_{2}^{N C}$ is greater than $t_{2}^{C}$ if parameter $\alpha$ is great enough $\left(\alpha>\alpha_{2}\right)$. Therefore, if $\alpha<\alpha_{2}$ both countries set a lower tax in the non-cooperative case (the same result as when $\alpha=0$ ). If $\alpha>\alpha_{1}$ both countries set a higher tax in the non-cooperative case. Finally, if $\alpha_{2}<\alpha<\alpha_{1}$, country 1 (2) sets a lower tax in the non-cooperative (cooperative) case.

As the taxes set in both countries are higher in the cooperative case than in the noncooperative case when parameter $\alpha$ is low enough, environmental damage is lower in the first case if parameter $\alpha$ is such that $\alpha<\alpha_{4}$. Note that if $\alpha=0$, environmental damage is lower in the cooperative case. Moreover, as the taxes set in both countries are higher in the noncooperative case when parameter $\alpha$ is great enough, environmental damage is lower in this case if parameter $\alpha$ is such that $\alpha>\alpha_{3}$. Finally, when $\alpha_{3}>\alpha>\alpha_{4}$ environmental damage is greater in the non-cooperative (cooperative) case in country 1 (2).

\section{Transboundary pollution.}

We assume in this section that firms produce a homogeneous good whose production process causes transboundary pollution. The environmental damage generated in country $i$ by firm $i$ is now defined by: $D_{i}=\lambda\left(e_{i}+s e_{j}\right)^{2}, i=1,2$, where parameter $s$ measures the 
degree to which environmental pollution spills over to trading partners (transboundary spillovers). Parameter $s$ varies between 0 and 1: $s=0$ means that damage is purely local, and $s=1$ means that emissions cause the same damage in the two countries. Transboundary spillovers increase with parameter $s$. The taxes set by the governments in the cooperative and non-cooperative cases are relegated to the appendix.

It can be proved that only when parameter $s$ is low enough can the taxes set by the governments in the non-cooperative case be greater than in the cooperative case (see Figure 1). In fact, if transboundary spillovers are great enough $(s \geq 0.0627)$, cooperative taxes are greater than non-cooperative taxes. When parameter $s$ is low enough $(s<0.0627)$, we obtain a similar result to when environmental damage is purely local.

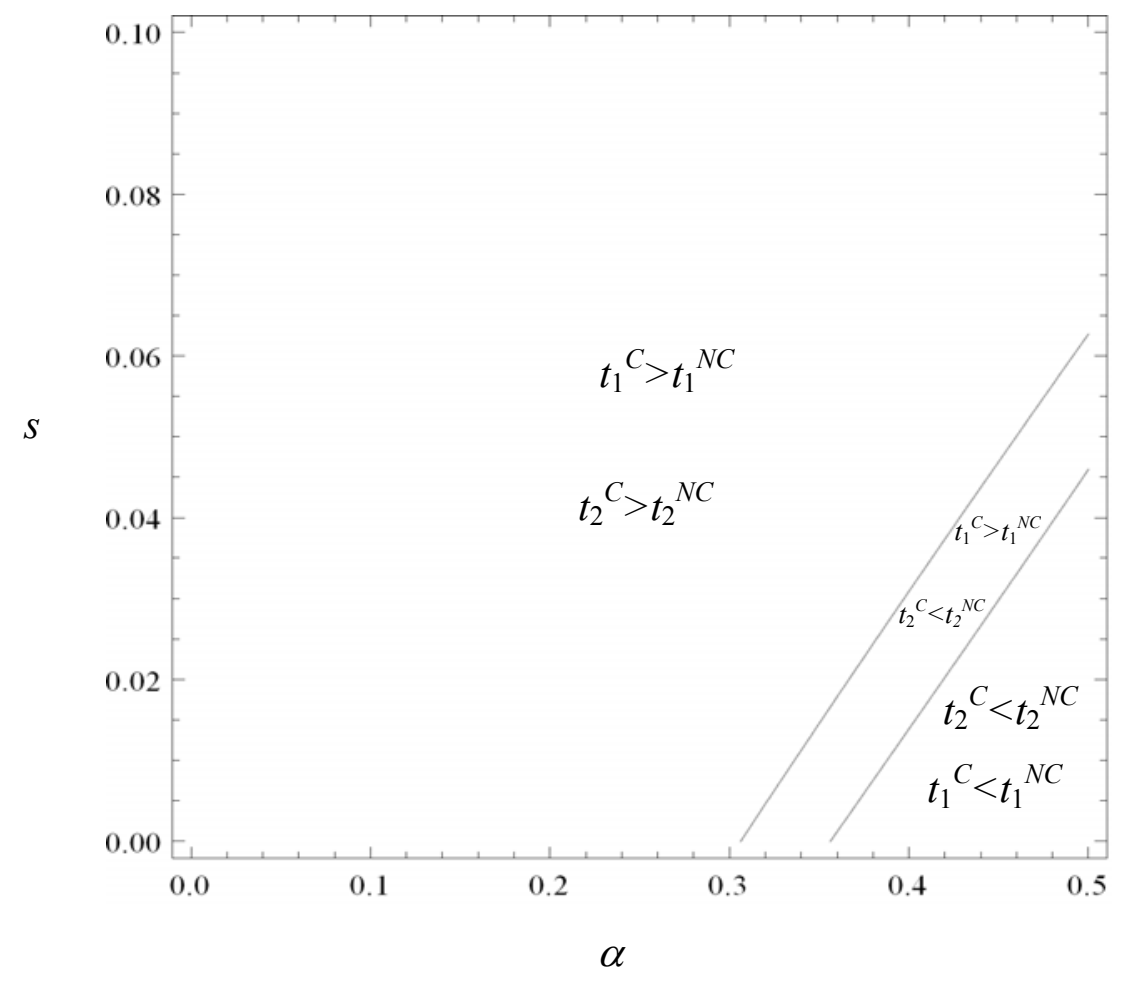

Figure 1. Comparison of taxes assuming transboundary spillovers.

When parameter $s$ is great enough, transboundary spillovers are also great enough which means that the incentive to transfer production (and thus pollution) to the other country is weaker. Thus, the greater the value of parameter $s$ the weaker the pollutionshifting effect is. Therefore, transboundary spillovers weaken the incentive of each government to raise the tax so as to send production abroad. As a result, when parameter $s$ 
is great enough the taxes set by governments are lower in the non-cooperative case than in the cooperative case for all values of parameter $\alpha$. This means that when transboundary spillovers are great enough the cross-ownership effect is weak enough to raise the taxes set by the governments above cooperative taxes.

\section{Conclusion}

There are many cases in which firms acquire a stake in their rivals that gives them a share in the profit but not in the decision making of those rivals. These passive investments affect the production and thus the pollutant emissions of the firms. As a result, partial crossownership affects the strategic environmental policy of governments. This issue has not been examined by the literature that analyzes the environmental policy of governments. Thus, this paper examines the setting of cooperative and non-cooperative environmental taxes by government when there is partial cross-ownership.

The design of environmental policy with imperfect competitive polluting industries has been analyzed considering different types of asymmetries between countries: sequential decisions on environmental taxes and various forms of international asymmetry. In this paper we consider a different asymmetry between governments. We assume that one firm owns a stake in its rival and that each firm is owned by investors of the country in which the firm is located. Thus, the ownership of the firms is asymmetrically distributed between the investors of the two countries.

When countries set the environmental taxes that maximize the joint welfare of the two countries we find that equilibrium taxes are not harmonized and the firm that owns a stake in its rival pays less tax than when partial cross-participation does not exist while the other firm pays more tax. This result is also obtained in the non-cooperative case. However, the effects explaining these results differ from one case to the other, since in the cooperative case taxes are chosen by efficiency reasons while in the non-cooperative case they are chosen for strategic reasons. A comparison of cooperative and non-cooperative taxes reveals that if the stake that one firm has in its rival is great enough both countries set a lower tax in the non-cooperative case. If that stake is low enough, both countries set a higher tax in the cooperative case. Finally, if the stake takes an intermediate value, the 
country whose firm has a stake in its rival sets a lower tax in the non-cooperative case while its rival sets a lower tax in the cooperative case.

One possible extension of the paper is to consider that the investors of each country own half of the stock of each firm. Thus, both countries obtain the same producer surplus. In that case, it can be shown that the tax set in the non-cooperative case is greater than the tax set in the cooperative case in both countries, and taxes are harmonized.

\section{Acknowledgements}

Financial support from Ministerio de Ciencia y Tecnología and FEDER (ECO2009-07939) and Departamento de Educación, Universidades e Investigación del Gobierno Vasco (IT223-07) is gratefully acknowledged.

\section{Appendix}

\section{Proof of proposition 1}

Let $K=1 /\left(95-18 \alpha+3 \alpha^{2}\right)$. By computing the taxes that maximize the joint welfare of the two countries we obtain:

$$
\begin{aligned}
& t_{1}^{C}=2 K(A-c)\left(10-8 \alpha+\alpha^{2}\right), t_{2}^{C}=K(A-c)\left(20+\alpha^{2}\right), t^{C}=4(A-c) / 19, \\
& q_{1}^{C}=K(A-c)\left(25-12 \alpha+2 \alpha^{2}\right), q_{2}^{C}=K(A-c)(25-3 \alpha), \\
& D_{1}^{C}=K^{2}(A-c)^{2}\left(15-4 \alpha+\alpha^{2}\right)^{2}, D_{2}^{C}=K^{2}(A-c)^{2}\left(30-6 \alpha-\alpha^{2}\right)^{2} / 4, \\
& W_{1}^{C}=K^{2}(A-c)^{2}\left(5700+60 \alpha-91 \alpha^{2}+40 \alpha^{3}+4 \alpha^{4}+\alpha^{5}\right) / 4, \\
& W_{2}^{C}=K^{2}(A-c)^{2}\left(5700-4880 \alpha+1145 \alpha^{2}-160 \alpha^{3}+2 \alpha^{4}-\alpha^{5}\right) / 4 .
\end{aligned}
$$

As $0<\alpha<1 / 2$ :

i) $\frac{\partial t_{1}^{C}}{\partial \alpha}=-4 K^{2}(A-c)\left(290-65 \alpha-3 \alpha^{2}\right)<0, \frac{\partial t_{2}^{C}}{\partial \alpha}=2 K^{2}(A-c)\left(180+35 \alpha-9 \alpha^{2}\right)>0$; 
ii) $\frac{\partial q_{1}^{C}}{\partial \alpha}=-230 K^{2}(A-c)(3-\alpha)<0, \frac{\partial q_{2}^{C}}{\partial \alpha}=3 K^{2}(A-c)\left(55-50 \alpha+3 \alpha^{2}\right)>0$;

$\frac{\partial e_{1}^{C}}{\partial \alpha}=-2 K^{2}(A-c)\left(55-50 \alpha+3 \alpha^{2}\right)<0, \frac{\partial e_{2}^{C}}{\partial \alpha}=-K^{2}(A-c)\left(15+185 \alpha-18 \alpha^{2}\right)<0 ;$

$\frac{\partial D_{1}^{C}}{\partial \alpha}=-K^{3}(A-c)^{2}\left(825-970 \alpha+300 \alpha^{2}-62 \alpha^{3}+3 \alpha^{4}\right)<0$,

$\frac{\partial D_{2}^{C}}{\partial \alpha}=-4 K^{3}(A-c)^{2}\left(450+5460 \alpha-1665 \alpha^{2}-77 \alpha^{3}+18 \alpha^{4}\right)<0$,

$D_{1}^{C}-D_{2}^{C}=-K^{2}(A-c)^{2} \alpha(2-3 \alpha)\left(60-14 \alpha+\alpha^{2}\right) / 4<0$.

iii) $\frac{\partial W_{1}^{C}}{\partial \alpha}=K^{3}(A-c)^{2}\left(210900-84610 \alpha+10860 \alpha^{2}+1346 \alpha^{3}+211 \alpha^{4}-54 \alpha^{5}+3 \alpha^{6}\right) / 4>0$,

$\frac{\partial W_{2}^{C}}{\partial \alpha}=-K^{3}(A-c)^{2}\left(258400-61310 \alpha+1680 \alpha^{2}+3230 \alpha^{3}+67 \alpha^{4}-54 \alpha^{5}+3 \alpha^{6}\right) / 4<0$,

$\frac{\partial\left(W_{1}^{C}+W_{2}^{C}\right)}{\partial \alpha}=-K^{2}(A-c)^{2}\left(125+85 \alpha-12 \alpha^{2}\right)<0$,

$W_{1}^{C}-W_{2}^{C}=K^{2}(A-c)^{2} \alpha\left(2470-618 \alpha+100 \alpha^{2}+\alpha^{3}+\alpha^{4}\right) / 2>0$.

\section{Non-cooperative taxes}

Let $H=1 /\left(1352-143 \alpha-105 \alpha^{2}+28 \alpha^{3}-2 \alpha^{4}\right)$. From (7) we obtain the taxes set by the governments, the abatement level, the output and the profit of firms, the consumer and producer surpluses, the environmental damage, the total taxes collected by the governments and social welfare:

$$
\begin{aligned}
& t_{1}^{N C}=H(A-c)\left(260-138 \alpha-5 \alpha^{2}+15 \alpha^{3}-2 \alpha^{4}\right), t_{2}^{N C}=2 H(A-c)\left(130+56 \alpha-19 \alpha^{2}+\alpha^{3}\right), \\
& t^{N C}=5(A-c) / 26, a_{1}^{N C}=t_{1}^{N C} / 2, q_{1}^{N C}=H(A-c)\left(364-161 \alpha-13 \alpha^{2}+18 \alpha^{3}-2 \alpha^{4}\right), \\
& a_{2}^{N C}=t_{2}^{N C} / 2, q_{2}^{N C}=H(A-c)\left(364-47 \alpha-27 \alpha^{2}+4 \alpha^{3}\right), \\
& C S_{1}^{N C}=C S_{2}^{N C}=H^{2}(A-c)^{2}\left(364-104 \alpha-20 \alpha^{2}+11 \alpha^{3}-\alpha^{4}\right)^{2}, \\
& \pi_{1}^{N C}=H^{2}(A-c)^{2}\left(597584-10608 \alpha-220576 \alpha^{2}+\right. \\
& \left.50368 \alpha^{3}+18377 \alpha^{4}-6362 \alpha^{5}-27 \alpha^{6}+156 \alpha^{7}-12 \alpha^{8}\right) / 4,
\end{aligned}
$$




$$
\begin{aligned}
& \pi_{2}^{N C}=H^{2}(A-c)^{2}\left(149396-19656 \alpha-19251 \alpha^{2}+3582 \alpha^{3}+826 \alpha^{4}-254 \alpha^{5}+17 \alpha^{6}\right), \\
& P S_{2}^{N C}=(1-\alpha) \pi_{2}^{N C}, P S_{1}^{N C}=\pi_{1}^{N C}+\alpha \pi_{2}^{N C}=H^{2}(A-c)^{2}(597584+586976 \alpha- \\
& \left.\quad 299200 \alpha^{2}-26636 \alpha^{3}+32705 \alpha^{4}-3058 \alpha^{5}-1043 \alpha^{6}+224 \alpha^{7}-12 \alpha^{8}\right) / 4, \\
& D_{1}^{N C}=H^{2}(A-c)^{2}\left(468-184 \alpha-21 \alpha^{2}+21 \alpha^{3}-2 \alpha^{4}\right)^{2} / 4, \\
& D_{2}^{N C}=H^{2}(A-c)^{2}\left(234-103 \alpha-8 \alpha^{2}+3 \alpha^{3}\right)^{2}, \\
& T_{1}^{N C}=H^{2}(A-c)^{2}\left(468-184 \alpha-21 \alpha^{2}+21 \alpha^{3}-2 \alpha^{4}\right)\left(260-138 \alpha-5 \alpha^{2}+15 \alpha^{3}-2 \alpha^{4}\right) / 2, \\
& T_{2}^{N C}=2 H^{2}(A-c)^{2}\left(130+56 \alpha-19 \alpha^{2}+\alpha^{3}\right)\left(234-103 \alpha-8 \alpha^{2}+3 \alpha^{3}\right), \\
& W_{1}^{N C}=H^{2}(A-c)^{2}\left(575952+115752 \alpha-146596 \alpha^{2}+\right. \\
& \left.13624 \alpha^{3}+8691 \alpha^{4}-1696 \alpha^{5}-95 \alpha^{6}+38 \alpha^{7}-2 \alpha^{8}\right) / 2, \\
& W_{2}^{N C}=H^{2}(A-c)^{2}\left(287976-197132 \alpha-32712 \alpha^{2}+\right. \\
& \left.36215 \alpha^{3}-4384 \alpha^{4}-1394 \alpha^{5}+429 \alpha^{6}-39 \alpha^{7}+\alpha^{8}\right) .
\end{aligned}
$$

\section{Proof of proposition 2}

As $0<\alpha<1 / 2$ :

i) $\frac{\partial t_{1}^{N C}}{\partial \alpha}=-H^{2}(A-c)\left(149396-41080 \alpha-25225 \alpha^{2}+5298 \alpha^{3}+1405 \alpha^{4}-400 \alpha^{5}+26 \alpha^{6}\right)<0$, $\frac{\partial t_{2}^{N C}}{\partial \alpha}=2 H^{2}(A-c)\left(94302-24076 \alpha+1733 \alpha^{2}-2382 \alpha^{3}+763 \alpha^{4}-76 \alpha^{5}+2 \alpha^{6}\right)>0 ;$

ii) $\frac{\partial q_{1}^{N C}}{\partial \alpha}=-2 H^{2}(A-c)\left(82810-20644 \alpha-13693 \alpha^{2}+2018 \alpha^{3}+817 \alpha^{4}-184 \alpha^{5}+10 \alpha^{6}\right)<0$,

$$
\frac{\partial q_{2}^{N C}}{\partial \alpha}=-2 H^{2}(A-c)\left(5746-1716 \alpha+7713 \alpha^{2}-2200 \alpha^{3}-27 \alpha^{4}+54 \alpha^{5}-4 \alpha^{6}\right)<0 \text {, }
$$$$
q_{1}^{N C}-q_{2}^{N C}=-2 H(A-c) \alpha\left(57-7 \alpha-7 \alpha^{2}+\alpha^{3}\right)<0 ;
$$$$
\frac{\partial \pi_{1}^{N C}}{\partial \alpha}=H^{3}(A-c)^{2}\left(78283504-173484584 \alpha+50278488 \alpha^{2}+28452848 \alpha^{3}-\right.
$$$$
\left.9209151 \alpha^{4}-2183775 \alpha^{5}+817203 \alpha^{6}+44745 \alpha^{7}-38508 \alpha^{8}+4650 \alpha^{9}-180 \alpha^{10}\right) / 2,
$$

$\frac{\partial \pi_{2}^{N C}}{\partial \alpha}=2 H^{3}(A-c)^{2}\left(8076172+3940404 \alpha-8380788 \alpha^{2}+\right.$

$$
\left.2527124 \alpha^{3}+151881 \alpha^{4}-142515 \alpha^{5}+3255 \alpha^{6}+5075 \alpha^{7}-762 \alpha^{8}+34 \alpha^{9}\right),
$$




$$
\begin{aligned}
& \pi_{1}^{N C}-\pi_{2}^{N C}=H^{2}(A-c)^{2} \alpha\left(68016-143572 \alpha+36040 \alpha^{2}+\right. \\
& \left.15073 \alpha^{3}-5346 \alpha^{4}-95 \alpha^{5}+156 \alpha^{6}-12 \alpha^{7}\right) / 4>0 ; \\
& \text { iii) } \frac{\partial C S_{1}^{N C}}{\partial \alpha}=\frac{\partial C S_{2}^{N C}}{\partial \alpha}=-4 H^{3}(A-c)^{2}\left(364-104 \alpha-20 \alpha^{2}+11 \alpha^{3}-\alpha^{4}\right) \\
& \left(44278-11180 \alpha-2990 \alpha^{2}-91 \alpha^{3}+395 \alpha^{4}-65 \alpha^{5}+3 \alpha^{6}\right)<0 ;
\end{aligned}
$$

iv) $\frac{\partial P S_{1}^{N C}}{\partial \alpha}=H^{3}(A-c)^{2}\left(482250288-237056976 \alpha-11766144 \alpha^{2}+22615146 \alpha^{3}+\right.$ $\left.4452787 \alpha^{4}-4250955 \alpha^{5}+469891 \alpha^{6}+138171 \alpha^{7}-39306 \alpha^{8}+3570 \alpha^{9}-112 \alpha^{10}\right) / 2>0$,

$$
\begin{aligned}
& \begin{aligned}
\frac{\partial P S_{2}^{N C}}{\partial \alpha}= & -H^{3}(A-c)^{2}\left(185831048-39667004 \alpha-14260740 \alpha^{2}-7973099 \alpha^{3}+\right. \\
& \left.+6527207 \alpha^{4}-748560 \alpha^{5}-180166 \alpha^{6}+36563 \alpha^{7}+1125 \alpha^{8}-608 \alpha^{9}+34 \alpha^{10}\right)<0,
\end{aligned} \\
& P S_{1}^{N C}-P S_{2}^{N C}=H^{2}(A-c)^{2} \alpha(1263184-300820 \alpha- \\
& \left.117968 \alpha^{2}+43729 \alpha^{3}+1262 \alpha^{4}-2127 \alpha^{5}+292 \alpha^{6}-12 \alpha^{7}\right) / 4>0 ;
\end{aligned}
$$

v) $\frac{\partial T_{1}^{N C}}{\partial \alpha}=-H^{3}(A-c)^{2}\left(58598384-41298868 \alpha-5124444 \alpha^{2}+9427363 \alpha^{3}-\right.$

$$
\begin{array}{r}
5124444 \alpha^{2}+9427363 \alpha^{3}-842932 \alpha^{4}-861540 \alpha^{5}+179684 \alpha^{6}+ \\
\left.22335 \alpha^{7}-10296 \alpha^{8}+1114 \alpha^{9}-40 \alpha^{10}\right)<0,
\end{array}
$$

$\frac{\partial T_{2}^{N C}}{\partial \alpha}=2 H^{3}(A-c)^{2}\left(8313448-17695314 \alpha+3450798 \alpha^{2}-968063 \alpha^{3}+\right.$

$$
\left.978947 \alpha^{4}-261999 \alpha^{5}+14287 \alpha^{6}+2926 \alpha^{7}-390 \alpha^{8}+12 \alpha^{9}\right)>0,
$$

$T_{1}^{N C}-T_{2}^{N C}=-H^{2}(A-c)^{2} \alpha\left(111280-62608 \alpha-7766 \alpha^{2}+\right.$

$$
\left.7877 \alpha^{3}-484 \alpha^{4}-355 \alpha^{5}+72 \alpha^{6}-4 \alpha^{7}\right) / 2<0
$$

$\frac{\partial D_{1}^{N C}}{\partial \alpha}=-H^{3}(A-c)^{2}\left(468-184 \alpha-21 \alpha^{2}+21 \alpha^{3}-2 \alpha^{4}\right)(181844-41496 \alpha-$

$$
\left.29547 \alpha^{2}+2774 \alpha^{3}+1863 \alpha^{4}-336 \alpha^{5}+14 \alpha^{6}\right) / 2<0,
$$

$\frac{\partial D_{2}^{N C}}{\partial \alpha}=-2 H^{3}(A-c)^{2}\left(234-103 \alpha-8 \alpha^{2}+3 \alpha^{3}\right)(105794-27508 \alpha+$

$$
\left.17159 \alpha^{2}-6782 \alpha^{3}+709 \alpha^{4}+32 \alpha^{5}-6 \alpha^{6}\right)<0,
$$

$D_{1}^{N C}-D_{2}^{N C}=H^{2}(A-c)^{2}(4-\alpha)(3-\alpha) \alpha\left(78+13 \alpha-2 \alpha^{2}\right)\left(22-5 \alpha+15 \alpha^{2}-2 \alpha^{3}\right) / 4>0 ;$

vi) $\frac{\partial W_{1}^{N C}}{\partial \alpha}=H^{3}(A-c)^{2}\left(160609488-68971604 \alpha-2519556 \alpha^{2}+3638744 \alpha^{3}+\right.$ 


$$
\begin{aligned}
& \left.2759607 \alpha^{4}-1473312 \alpha^{5}+120798 \alpha^{6}+44082 \alpha^{7}-10215 \alpha^{8}+762 \alpha^{9}-18 \alpha^{10}\right)>0, \\
& \frac{\partial W_{2}^{N C}}{\partial \alpha}=-H^{3}(A-c)^{2}\left(184161328-4306796 \alpha-36411492 \alpha^{2}+3550841 \alpha^{3}+\right. \\
& \left.\quad 3463145 \alpha^{4}-643470 \alpha^{5}-139540 \alpha^{6}+47429 \alpha^{7}-3063 \alpha^{8}-204 \alpha^{9}+22 \alpha^{10}\right)<0, \\
& \frac{\partial\left(W_{1}^{N C}+W_{2}^{N C}\right)}{\partial \alpha \quad}=-H^{3}(A-c)^{2}\left(23551840+64664808 \alpha-33891936 \alpha^{2}-87903 \alpha^{3}+\right. \\
& \left.\quad 703538 \alpha^{4}+829842 \alpha^{5}-260338 \alpha^{6}+3347 \alpha^{7}+7152 \alpha^{8}-966 \alpha^{9}+40 \alpha^{10}\right)<0, \\
& W_{1}^{N C}-W_{2}^{N C}=H^{2}(A-c)^{2} \alpha(510016-81172 \alpha- \\
& \left.58806 \alpha^{2}+17459 \alpha^{3}+1092 \alpha^{4}-953 \alpha^{5}+116 \alpha^{6}-4 \alpha^{7}\right) / 2>0 .
\end{aligned}
$$

\section{Proof of proposition 3}

Comparing the taxes and the environmental damage in the two cases considered we obtain:

i) $t_{1}^{C}-t_{1}^{N C}=K H(A-c)\left(2340-6702 \alpha+103 \alpha^{2}+835 \alpha^{3}-223 \alpha^{4}+7 \alpha^{5}+2 \alpha^{6}\right)$. It can be shown that $\left(2340-6702 \alpha+103 \alpha^{2}+835 \alpha^{3}-223 \alpha^{4}+7 \alpha^{5}+2 \alpha^{6}\right)$ decreases strictly with parameter $\alpha$, and that it is positive for $\alpha=0$ and negative for $\alpha=1 / 2$; therefore, there exists a value of parameter $\alpha$, denoted as $\alpha_{1}\left(\alpha_{1} \approx 0.3563\right)$, such that $t_{1}^{C}-t_{1}^{N C}>0$ if and only if $\alpha<\alpha_{1}$.

ii) $t_{2}^{C}-t_{2}^{N C}=K H(A-c)\left(2340-8820 \alpha+4098 \alpha^{2}-793 \alpha^{3}+5 \alpha^{4}+22 \alpha^{5}-2 \alpha^{6}\right)$. It can be shown that $\left(2340-8820 \alpha+4098 \alpha^{2}-793 \alpha^{3}+5 \alpha^{4}+22 \alpha^{5}-2 \alpha^{6}\right)$ decreases strictly with parameter $\alpha$, and that it is positive for $\alpha=0$ and negative for $\alpha=1 / 2$; therefore, there exists a value of parameter $\alpha$, denoted as $\alpha_{2}\left(\alpha_{2} \approx 0.3063\right)$, such that $t_{2}^{C}-t_{2}^{N C}>0$ if and only if $\alpha<\alpha_{2}$.

iii) $D_{1}^{C}-D_{1}^{N C}=-K^{2} H^{2}(A-c)^{2}\left(3900-10798 \alpha+2023 \alpha^{2}+427 \alpha^{3}-137 \alpha^{4}+27 \alpha^{5}-2 \alpha^{6}\right)$

$$
\left(85020-41010 \alpha+3419 \alpha^{2}+3215 \alpha^{3}-1125 \alpha^{4}+171 \alpha^{5}-10 \alpha^{6}\right) / 4 .
$$

It can be shown that $\left(85020-41010 \alpha+3419 \alpha^{2}+3215 \alpha^{3}-1125 \alpha^{4}+171 \alpha^{5}-10 \alpha^{6}\right)$ is positive. Moreover, $-\left(3900-10798 \alpha+2023 \alpha^{2}+427 \alpha^{3}-137 \alpha^{4}+27 \alpha^{5}-2 \alpha^{6}\right)$ increases 
strictly with parameter $\alpha$, it is negative for $\alpha=0$ and positive for $\alpha=1 / 2$; therefore, there exists a value of parameter $\alpha$, denoted as $\alpha_{3}\left(\alpha_{3} \approx 0.3920\right)$, such that $D_{1}^{C}-D_{1}^{N C}>0$ if and only if $\alpha>\alpha_{3}$.

iv) $D_{2}^{C}-D_{2}^{N C}=-K^{2} H^{2}(A-c)^{2}\left(3900-15592 \alpha+7236 \alpha^{2}-1373 \alpha^{3}-33 \alpha^{4}+34 \alpha^{5}-2 \alpha^{6}\right)$

$$
\left(85020-40396 \alpha-52 \alpha^{2}+1853 \alpha^{3}-279 \alpha^{4}+2 \alpha^{5}+2 \alpha^{6}\right) / 4 .
$$

It can be shown that $\left(85020-40396 \alpha-52 \alpha^{2}+1853 \alpha^{3}-279 \alpha^{4}+2 \alpha^{5}+2 \alpha^{6}\right)$ is positive. Moreover, $-\left(3900-15592 \alpha+7236 \alpha^{2}-1373 \alpha^{3}-33 \alpha^{4}+34 \alpha^{5}-2 \alpha^{6}\right)$ increases strictly with parameter $\alpha$, it is negative for $\alpha=0$ and positive for $\alpha=1 / 2$; therefore, there exists a value of parameter $\alpha$, denoted as $\alpha_{4}\left(\alpha_{4} \approx 0.2860\right)$, such that $D_{2}^{C}-D_{2}^{N C}>0$ if and only if $\alpha>\alpha_{4}$.

\section{Transboundary spillovers}

When there is transboundary pollution, environmental damage in country $i$ is defined as: $D_{i}=\lambda\left(e_{i}+s e_{j}\right)^{2}, \quad i \neq j ; i, j=1,2$. Let $T_{1}=\left(s^{4}(-15+\alpha)^{2}+8 s\left(-23-2 \alpha+\alpha^{2}\right)+4\left(95-18 \alpha+3 \alpha^{2}\right)+s^{2}(-\right.$ $\left.\left.308+28 \alpha+6 \alpha^{2}\right)\right)$, and $T_{2}=\left(1352-143 \alpha-105 \alpha^{2}+28 \alpha^{3}-2 \alpha^{4}+4 s^{4}\left(-15-14 \alpha+\alpha^{2}\right)+2 s^{3}(210+61 \alpha-\right.$ $\left.\left.\left.20 \alpha^{2}+\alpha^{3}\right)-s^{2}\left(623-373 \alpha+11 \alpha^{2}+3 \alpha^{3}\right)-2 s\left(377+163 \alpha-65 \alpha^{2}+5 \alpha^{3}\right)\right)\right)$. Assuming $\lambda=1$, we obtain in the cooperative case that:

$$
\begin{aligned}
& t_{1}{ }^{C}=\left(2(A-c)\left(4 s(7+2 \alpha)+s^{4}\left(45-18 \alpha+\alpha^{2}\right)+4(10-8 \alpha+\alpha 2)+s^{2}\left(-94+22 \alpha+\alpha^{2}\right)\right)\right) /\left(T_{1}\right), \\
& t_{2}{ }^{C}=\left(2(A-c)\left(3 s^{4}(15-\alpha)+2\left(20+\alpha^{2}\right)+2 s\left(14-10 \alpha+\alpha^{2}\right)-2 s^{2}\left(47-4 \alpha-\alpha^{2}\right)\right)\right) /\left(T_{1}\right) .
\end{aligned}
$$

In the non-cooperative case:

$$
\begin{aligned}
& t_{1}{ }^{N C}=-\left(( \mathrm { A } - \mathrm { c } ) \left(-260+138 \alpha+5 \alpha^{2}-15 \alpha^{3}+2 \alpha^{4}-8 \mathrm{~s}^{4}\left(-3-2 \alpha+\alpha^{2}\right)-2 \mathrm{~s}^{2}\left(-157+104 \alpha-20 \alpha^{2}+\alpha^{3}\right)-\right.\right. \\
& \left.\left.4 s^{3}\left(42+\alpha-8 \alpha^{2}+\alpha^{3}\right)+s\left(10+69 \alpha-38 \alpha^{2}+7 \alpha^{3}\right)\right)\right) /\left(T_{2}\right),
\end{aligned}
$$

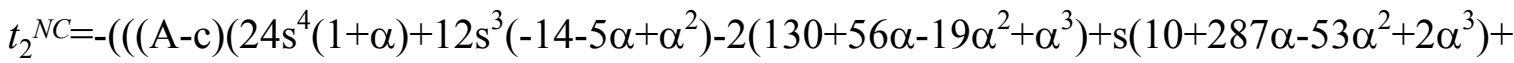

$$
\begin{aligned}
& \left.\left.2 \mathrm{~s}^{2}\left(157-55 \alpha-14 \alpha^{2}+2 \alpha^{3}\right)\right)\right) /\left(T_{2}\right) \text {. }
\end{aligned}
$$


Comparing the taxes set in the two cases:

$$
\begin{array}{r}
t_{1}{ }^{C}-t_{1}{ }^{N C}=\left(( \mathrm { A } - \mathrm { c } ) \left(2 s^{6}\left(-9234-1705 \alpha+195 \alpha^{2}+525 \alpha^{3}-73 \alpha^{4}+4 \alpha^{5}\right)+2 s^{3}\left(-7884-22382 \alpha+9990 \alpha^{2}-\right.\right.\right. \\
\left.843 \alpha^{3}-158 \alpha^{4}+13 \alpha^{5}\right)+s^{5}\left(100602+2323 \alpha-14806 \alpha^{2}+2916 \alpha^{3}-396 \alpha^{4}+33 \alpha^{5}\right)+ \\
s^{2}\left(148680+38524 \alpha-29156 \alpha^{2}+5878 \alpha^{3}-544 \alpha^{4}+58 \alpha^{5}-8 \alpha^{6}\right)+s^{4}\left(-142344+26684 \alpha+11835 \alpha^{2}-\right. \\
\left.3669 \alpha^{3}+175 \alpha^{4}-3 \alpha^{5}+2 \alpha^{6}\right)-4\left(2340-6702 \alpha+103 \alpha^{2}+853 \alpha^{3}-223 \alpha^{4}+7 \alpha^{5}+2 \alpha^{6}\right)- \\
\left.\left.4 s\left(16758+10017 \alpha-1858 \alpha^{2}-458 \alpha^{3}+242 \alpha^{4}-45 \alpha^{5}+4 \alpha^{6}\right)\right)\right) /\left(T_{1} T_{2}\right), \\
t_{2}{ }^{C-t_{2}}{ }^{N C=-\left(( A - c ) \left(-2 s^{3}\left(-7884-10594 \alpha+5756 \alpha^{2}-969 \alpha^{3}+65 \alpha^{4}\right)+2 s^{6}\left(9234+2993 \alpha-3493 \alpha^{2}+\right.\right.\right.} \\
\left.705 \alpha^{3}-57 \alpha^{4}+2 \alpha^{5}\right)+s^{5}\left(-100602+31483 \alpha-69 \alpha^{2}-97 \alpha^{3}-93 \alpha^{4}+10 \alpha^{5}\right)+2 s^{4}(71172-34565 \alpha+ \\
\left.3319 \alpha^{2}+1122 \alpha^{3}-263 \alpha^{4}+15 \alpha^{5}\right)+4\left(2340-8820 \alpha+4098 \alpha^{2}-793 \alpha^{3}+5 \alpha^{4}+22 \alpha^{5}-2 \alpha^{6}\right)- \\
4 \mathrm{~s}\left(-16758-11235 \alpha+8833 \alpha^{2}-2494 \alpha^{3}+394 \alpha^{4}-40 \alpha^{5}+2 \alpha^{6}\right)-4 s^{2}\left(37170-25 \alpha-6670 \alpha^{2}+\right. \\
\left.\left.\left.1832 \alpha^{3}-93 \alpha^{4}-20 \alpha^{5}+2 \alpha^{6}\right)\right)\right) /\left(T_{1} T_{2}\right) .
\end{array}
$$




\section{References}

Alley, W., 1997. Partial ownership arrangements and collusion in the automobile industry. Journal of Industrial Economics 45 (2), 191-205.

Bárcena-Ruiz, J.C., 2006. Environmental taxes and first-mover advantages. Environmental and Resource Economics 35 (1), 19-39.

Bárcena-Ruiz, J.C., Garzón, M.B., 2003. Strategic environmental standards, wage incomes and the location of polluting firms. Environmental and Resource Economics 24 (2), 121-139.

Bárcena-Ruiz, J.C., Garzón, M.B., 2006. Mixed oligopoly and environmental policy. Spanish Economic Review 8 (2), 139-160.

Barnett, A.H., 1980. The Pigouvian tax rule under monopoly. American Economic Review 70 (5), 1037-1041.

Barrett, S., 1994. Strategic environmental policy and international trade. Journal of Public Economics 54 (3), 325-338.

Buchanan, J., 1969. External diseconomies, corrective taxes, and market structure. American Economic Review 59 (1), 174-177.

Carlsson, F., 2000. Environmental taxation and strategic commitment in duopoly models. Environmental and Resource Economics 15 (3), 243-256.

Conrad, K., 1993. Taxes and subsidies for pollution intensive industries as trade policy. Journal of Environmental Economics and Management 25 (2), 121-135.

Conrad, K., 1996a. Optimal environmental policy for oligopolistic industries under intraindustry trade. In Carraro, C., Katsoulacos, Y., Xepapadeas, A., (Eds.), Environmental Policy and Market Structure. Netherlands, Kluwer Academic Publishers.

Conrad, K., 1996b. Choosing emission taxes under international price competition. In Carraro, C., Katsoulacos, Y., Xepapadeas, A., (Eds.), Environmental Policy and Market Structure. Netherlands, Kluwer Academic Publishers.

Duval, T.Y., Hamilton, S.F., 2002. Strategic environmental policy and international trade in asymmetric oligopoly markets. International Tax and Public Finance 9 (3), 259-271.

Eerola, E., 2004. Environmental tax competition in the presence of multinational firms. International Tax and Public Finance 11 (3), 283-298. 
European Environmental Agency, 2007. Europe's environment: The fourth assessment. Environmental Assessment Report 1, www.eea.europa.eu/publications.

Falk, I., Mendelson, R., 1993. The economics of controlling stock pollutants: An efficient strategy for greenhouse gases. Journal of Environmental Economics and Management 25 (1), 75-88.

Farrell, J., Shapiro, C., 1990. Asset ownership and market structure in oligopoly. RAND Journal of Economics 21 (2), 275-292.

Fujiwara, K., 2009. Environmental Policies in a differentiated oligopoly revisited. Resource and Energy Economics 31 (3), 239-247.

Gilo, D., Moshe, Y., Spiegel, Y., 2006. Partial cross ownership and tacit collusion. RAND Journal of Economics 37 (1), 81-99.

Katsoulacos, Y., Xepapadeas, A., 1995. Environmental policy under oligopoly with endogenous market structure. Scandinavian journal of Economics 97 (3), 411-420.

Katsoulacos, Y., Xepapadeas, A., 1996. Emission taxes and market structure. In Carraro, C., Katsoulacos, Y., Xepapadeas, A., (Eds.), Environmental Policy and Market Structure. Netherlands, Kluwer Academic Publishers.

Kennedy, P.W., 1994. Equilibrium pollution taxes in open economies with imperfect competition. Journal of Environmental Economics and Management 27 (1), 49-63.

Lange, A., Requate, T., 1999. Emission taxes for price-setting firms: differentiated commodities and monopolistic competition. In: Petrakis, E., Sartzetakis, E.S., Xepapadeas, A., (Eds.). Environmental Regulation and Market Power: Competition, Time Consistency and International Trade, Edward Elgar, Cheltenham, UK.

Malueg, D., 1992. Collusive behaviour and partial ownership of rivals. International Journal of Industrial Organization 10 (1), 27-34.

Markusen, J.R., 1997. Costly pollution abatement, competitiveness and plant location decisions. Resource and Energy Economics 19 (4), 299-320.

Ono, H., Nakazato, T., Davis, C., Alley, W., 2004. Partial ownership arrangements in the Japanese automobile industry: 1990-2000. Journal of Applied Economics 7 (2), 355-367.

Rauscher, M., 1995. Environmental regulation and the location of polluting industries. International Tax and Public Finance 2 (2), 229-244. 
Requate, T., 2006. Environmental policy under imperfect competition. In: Tietenberg, T., Folmer, H., (Eds.), The International Yearbook of Environmental and Resource Economics 2006/2007. A Survey of Current Issues, Edward Elgar.

Reynolds, R.J., Snapp, B.R., 1986. The competitive effects of partial equity interests and joint ventures. International Journal of Industrial Organization 4 (2), 141-153.

Simpsom, R.D., 1995. Optimal pollution taxation in a Cournot duopoly. Environmental and Resource Economics 6 (4), 359-369.

Ulph, A., 1996. Environmental policy instruments and imperfectly competitive international trade. Environmental and Resource Economics 7 (4), 333-355.

Van der Ploeg, F., de Zeeuw, A.J., 1992. International aspects of pollution control. Environmental and Resource Economics 2, 117-139. 